\title{
TINGKAT PENGETAHUAN, SIKAP, DAN PERSEPSI TENAGA KESAHATAN TERHADAP KEHALALAN OBAT DI RUMAH SAKIT KABUPATEN BANYUMAS
}

\author{
${ }^{1}$ Alfiyaturrohmaniyah Trisnawati, ${ }^{2}$ Anjar Mahardian Kusuma \\ ${ }^{1,2}$ Fakultas Farmasi, Universitas Muhammadiyah Purwokerto \\ email: alfi.adwa8@gmail.com
}

\begin{abstract}
ABSTRAK
Tenaga kesehatan memiliki peran yang penting dalam pemilihan obat untuk pasien khususnya di kalangan dokter dan apoteker. Dokter dan apoteker memiliki peran terbesar dalam pemilihan obat untuk pasien. Saat ini pemilihan obat oleh dokter dan apoteker beberapa belum mengerti dan belum paham tentang hukumnya menggunakan obat-obatan yang mengandung bahan yang dilarang menurut Islam. Tujuan penelitian ini adalah untuk mengukur tingkat pengetahuan, sikap, dan presepsi tenaga kesehatan di rumah sakit Kabupaten Banyumas terhadap kehalalan obat. Penelitian ini mengunakan pendekatan cross sectional pada periode waktu bulan Februari hingga Juni. Penelitian ini termasuk jenis penelitian deskriptif dengan cara penyebaran kuesioner kepada responden dan metode pengambilan data secara accidental sampling dan pemilihan dari dokter dan apoteker yang bekerja di rumah sakit di wilayah Kabupaten Banyumas. Berdasarkan hasil yang didapatkan bahwa pengetahuan responden baik 73 responden (96\%), sikap positif sebanyak 74 responden (97\%), dan persepsi baik 76 responden $(100 \%)$. Berdasarkan hasil tersebut dapat disimpulkan bahwa pengetahuan dokter dan apoteker baik, serta sikap dan persepsidokter dan apoteker pun baik.
\end{abstract}

Kata Kunci: Pengetahuan, Sikap, Persepsi, Kehalalan Obat

\begin{abstract}
Health workers have an important role in the selection of drugs for patients, especially among doctors and pharmacists. Doctors and pharmacists have the greatest role in the selection of drugs for patients. Currently the selection of drugs by some doctors and pharmacists don't understand and have'nt understand the law using drugs medicines containing material prohibited by Islam. The purpose of this study was to measure the level of knowledge, attitudes, and perceptions of health workers at the Banyumas Regency hospital on halal drug. This was a cross-sectional study, carried out in the period of February to June. This research includes descriptive research type by way of distributing questionnaires to respondents and accidental sampling and selection method of sampling from doctors and pharmacists who work in hospitals in Banyumas regency. Based on the results obtained that knowledge of good respondents 73 respondents (96\%), positive attitude as much as 74 respondents (97\%), and good perceptions 76 respondents $(100 \%)$. Based on these results can be concluded that the knowledge of doctors and pharmacists good, as well as attitude and perceptions doctors and pharmacists is good.
\end{abstract}

Key words: Knowledge, Attitude, Perception, Halal Pharmaceutical 
Tingkat Pengetahuan, Sikap, dan Persepsi Tenaga Kesehatan..

\section{PENDAHULUAN}

Kesehatan merupakan salah satu nikmat terindah dari Allah SWT. Obat menjadi kebutuhan manusia sebagai upaya untuk mengurangi dan menghilangkan rasa sakit yang dideritanya. Obat memiliki peran penting dalam proses penurunan angka kesakitan dan mortalitas serta dalam meningkatkan kualitas hidup seseorang. Sebuah obat terdiri dari kombinasi bahan aktif, dan bahan pembantu, bahan ini dapat diperoleh dari berbagai senyawa, hewan, tanaman atau asal sintetis (Hoesli \& Smith, 2011). Dalam kasus sumber bahan hewani, tidak menutup kemungkinan obat terbuat dari babi, hewan yang mati atau darah hewan. Beberapa contoh obat yang di dalamnya mengandung babi antara lain: Insulin, Lovenox, Cereblyosin dll. Selain itu, ada beberapa vaksin yang terkontaminasi dengan enzim tripsin dari babi, seperti vaksin polio dan hepatitis. Semua itu haram / dilarang untuk Muslim seperti disebutkan dalam AlQur'an. Sehingga, beberapa umat Islam mempertanyakan tentang kebolehan dan keabsahan (halal) mengkonsumsi obat dari sudut pandang Islam.

Menurut Dr. Anna P. Roswiem, wakil direktur LPPOM MUI, proses pembuatan obat menggunakan bahan eksipien. Pada bahan eksipien dalam pembuatan tablet ada beberapa yang memungkinkan bahan yang berasal dari lemak babi misalnya, magnesium stearat (garam asam lemak), monogliserida (bahan turunan lemak atau minyak), gelatin dan gliserol yang berpeluang berasal dari tulang atau kulit babi. Selain itu menurut Prof. Dr. H. Jurnalis Uddin, PAK dari Universitas YARSI, ada vaksin yang dibuat dengan bahan berasal dari embrio hewan atau manusia, seperti Hepatitis A dan Smallpox.

Sejalan dengan firman Allah SWT dalam Al Qur'an tentang larangan untuk mengkonsumsi darah dan daging babi, namun sebagai bentuk untuk mempertahankan kehidupan manusia Allah SWT memperbolehkan dengan alasan darurat.Pada penelitian Asmak ada beberapa bahan obat dengan alasan darurat masih boleh digunakan sebagai pengobatan penyakit, beberapa bahan obat yang diperbolehkan karena tidak adanya alternatif antara lain alkohol, gelatin, dan obat berbahaya.

“Dari Abu Darda', ia berkata: Rasulullah SAW bersabda: Sesungguhnya Allah telah menurunkan penyakit dan obat bagi setiap penyakit, maka berobatlah dan janganlah berobat dengan yang haram". (HR. Abu Dawud). dari hadist tersebut, tampak jelas perintah untuk berobat dengan yang halal. Sehingga dalam pemilihan obat untuk pengobatan seseorang harus 
mempertimbangkan kehalalan dari obat tersebut.

Tenaga kesehatan memiliki peran yang penting dalam pemilihan obat untuk pasien khususnya di kalangan dokter dan apoteker.Dokter dan apoteker memiliki peran terbesar dalam pemilihan obat untuk pasien. Saat ini pemilihan obat oleh dokter dan apoteker beberapa belum mengerti dan belum paham tentang hukumnya menggunakan obatobatan yang mengandung bahan yang dilarang menurut Islam. Sehingga dalam pemilihan obat untuk pasien, pertimbangan halal dan haramnya obat tersebut belum menjadi salah satu prioritas, sedangkan masyarakat di Kabupaten Banyumas mayoritas beragama Islam.

Berdasarkan uraian diatas, penelitian ini dilakukan untuk mengukur tingkat pengetahuan, sikap, dan persepsi tenaga kesehatan terhadap kehalalan obat di rumah sakit Kabupaten Banyumas.

\section{METODE}

Penelitian ini merupakan jenis penelitian deskriptif dengan model menggunakan pendekatan cross sectional. Cara penetapan sampel dilakukan dengan proportional random sampling. Responden penelitian dipilih dengan accidental sampling dan pemilihan secara tidak acak oleh pihak rumah sakit. Jumlah responden pada penelitian ini sejumlah 85 responden yang terdiri atas 43 dokter dan 42 apoteker. Penelitian ini dilakukan di 10 rumah sakit yang tersebar di kabupaten Banyumas pada bulan Febaruari hingga Juni 2017.

Instrument penelitian ini adalah kuesioner dengan menggunakan skala Guttman dan skala Likert. Yang diamati pada penelitian ini ialah tingkat pengetahuan, sikap, dan persepsi tenaga kesehatan terhadap kehalalan obat.

Data yang dikumpulkan dalam penelitian ini adalah data primer, yaitu data yang diperoleh langsung dari responden melalui pengisian kuesioner terstruktur. Analisis data dilaksanakan tiga tahap. Tahap pertama kuesioner dilakukan uji validasi. Uji validasi dilakukan untuk mengtahui apakah kuesioner penelitian tersebut valid atau tidak. Valid artinya alat tersebut mengukur apa yang ingin diukur. Tahap kedua ialah uji reliabilitas. Uji reliabilitas dilakukan untuk mengetahui apakah kuesioner tersebut reliabel atau tidak. Reliabilitas artinya kestabilan pengukuran, pertanyan dikatakan reliabel jika jawaban seseorang terhadap pertanyaan konsisten atau stabil dari waktu kewaktu. Untuk mengetahuai alat ukur yang dipakai reliabel untuk analisis jenis pertanyaan yang menggunakan skala Likert maka digunakan rumus "Cronbach's Alpha" (Riyanto, 2011). 
Tingkat Pengetahuan, Sikap, dan Persepsi Tenaga Kesehatan..

Tahap ketiga ialah analisis univariat. Analisis univariat digunakan untuk mendapatkan gambaran distribusi subyek penelitian masing-masing variabel dari pengetahuan, sikap dan persepsi tenaga kesehatan terhadap kehalalan obat di rumah sakit wilayah Kabupaten Banyumas. Bertujuan untuk menjelaskan karakteristik sikap variabel peneliti (Riyanto, 2011).

\section{HASIL DAN PEMBAHASAN}

Karakteristik responden merupakan gambaran mengenai responden penelitian ini. Deskripsi karakteristik responden dikelompokkan menjadi beberapa kelompok meliputi usia, jenis kelamin, pendidikan terakhir, profesi, dan lama bekerja seperti terlihat pada tabel 1 .

Tabel 1. Deskrispi Karakteristik Responden

\begin{tabular}{ccc}
\hline Karakteristik & $\begin{array}{c}\text { Karakteristik } \\
\text { demografi }\end{array}$ & Persentase (\%) \\
\hline \multirow{3}{*}{ Umur/usia (21-60) } & $21-30$ & 60 \\
& $31-40$ & 20 \\
& $41-50$ & 13 \\
Jenis Kelamin & $51-60$ & 3 \\
& Laki-laki & 40 \\
Pendidikan & Perempuan & 60 \\
\hline \multirow{2}{*}{ Profesi/pekerjaan } & S1/profesi & 85 \\
& S2 & 15 \\
\hline \multirow{2}{*}{ Lama Bekerja } & Dokter Umum & 50 \\
& Dokter Spesialis & 8 \\
& Apoteker & 42 \\
\hline & $1-10$ & 80 \\
& $11-20$ & 11 \\
\hline
\end{tabular}

Sumber: Data primer,2017

Pada hasil uji validitas menunjukkan bahwa validasi pertama terdapat 4 pertanyaan yang tidak valid sehingga memberikan hasil uji reliabilitas yang kurang. Kemudian pertanyaan yang tidak valid diperbaiki dan dilakukan uji validitas ulang yang memberikan hasil bahwa pertanyaan tersebut valid serta memberikan hasil uji reliabilitas yang sesuai atau pertanyaan dikatakan reliabel.

Uji validitas dan reliabilitas kuisioner sebanyak 30 pernyataan tingkat pengetahuan, sikap, dan persepsi. Masing-masing pernyataan dikatakan valid apabila nilai $r$ hitung $>\mathrm{r}$ tabel (Riyanto, 2011). Menurut Arikunto (2010) mengatakan $\mathrm{r}$ tabel untuk jumlah responden 30 
orang dengan taraf kepercayaan $95 \%(\sigma=5 \%)$ adalah 0,361(Sugiyono, 2011). Uji validitas untuk pengetahuan dilakukan menggunakan analisis koefisien korelasi biserial sedangkan sikap dan persepsi menggunakan analisis corelasi person product moment. Uji reliabilitas untuk pengetahuan dilakukan menggunakan menggunakan rumus KR-20 dan menggunakan Cronbach's Alphauntuk sikap dan persepsi.

Berdasarkan hasil penelitian dan setelah dilakukan tabulasi data diperoleh hasil nilai tingkat pengetahuan tenaga kesehatan terhadap kehalalan obat dikategorikan memiliki hasil yang baik seperti pada tabel 2. Hasil dari penilaian sikap tenaga kesehatan terhadap kehalalan obat menunjukkan hasil yang baik seperti pada tabel 3 serta hasil presepsi tenaga kesehatan terhadap kehalalan obat menunjukkan hasil yang baik pula terlihat pada tabel 4.

Penelitian ini bertujuan untuk mengukur tingkat pengetahuan, sikap, dan persepsi tenaga kesehatan terhadap kehalalan obat di rumah sakit kabupaten Banyumas. Jumlah responden yang berpartisipasi sejulah 85 orang yang terdiri atas 43 dokter dan 42 apoteker.

Berdasarkan tabel 1 dapat dilihat karakteristik responden berdasarkan usia menunjukkan usia responden di dominasi antara usia 21 tahun sampai dengan 30 tahun yaitu sebanyak 54 orang. Hal tersebut menunjukkan bahwa responden penelitian kali ini didominasi oleh para pegawai rumah sakit yang masih muda atau masih tergolong baru.

Karakteristik pada jenis kelamin, responden laki-laki sekitar 40\% yaitu sebanyak 34 orang lebih sedikit dibandingkan dengan jenis kelamin perempuan sekitar $60 \%$ yaitu sebanyak 51 orang. Hal tersebut menunjukkan bahwa responden perempuan lebih banyak dibandingkan dengan laki-laki.

Selanjutnya tingkat pendidikan responden sekitar $85 \%$ pada tingkat pendidikan sarjana atau profesi yaitu sebanyak 72 orang sedangkan pada tingkat pendidikan tinggi master yaitu sebanyak 13 orang sekitar $15 \%$. Hal tersebut menunjukkan bahwa sebagian besar responden penelitian ini memiliki pendidikan akhir yaitu tingkat sarjana/profesi.

Profesi/ pekerjaan responden mayoritas adalah apoteker dengan presentase (50\%) yang berarti sebagian dari total responden berprofesi sebagai apoteker. Selanjutnya responden berprofesi sebagai dokter umum dengan presentase $42 \%$ dan yang paling rendah ialah responden yang berprofesi sebagai dokter spesialis yaitu $8 \%$ dari keseluruhan responden. Karakteristik responden berdasarkan lama bekerja kebanyakan responden sudah bekerja pada rentang waktu 1 sampai dengan 10 tahun 
Tingkat Pengetahuan, Sikap, dan Persepsi Tenaga Kesehatan..

yaitu berjumlah 68 orang dengan presentase $80 \%$. Selanjutnya pada rentang waktu 11 sampai dengan 20 tahun yaitu berjumlah 9 orang dengan presentase $11 \%$. Dan yang terendah yaitu responden yang bekerja pada rentang waktu 21 sampai dengan 30 tahun yaitu berjumlah 8 orang dengan presentase $9 \%$. Hal tersebut menunjukkan bahwa responden pada penelitian ini didominasi oleh para pegawai rumah sakit yang baru atau belum lama bekerja di rumah sakit tersebut. Penelitian oleh Shadeqaa presentasi tersbesar lama bekerja ialah pada rentang 11-20 tahun dan 21-30 tahun.

Tingkat pengetahuan dalam penelitian ini digunakan untuk mengetahui tingkat pengetahuan tenaga kesehatan khususnya dokter dan apoteker terhadap kehalan obat. Sebelum mengerjakan pertanyaan tingkat pengetahuan tentang kehalalan obat, terdapat 3 pertanyaan pendahuluan untuk mengukur apakah responden familiar dengan kata halal haram atau tidak.

Pertanyaan pertama yaitu Apakah Anda mengetahui akan istilah/kata "Halal"? Jawaban dari pertanyaan pertama ialah seluruh reponden (100\%) menjawab bahwa mereka mengetahui istilah atau kata halal. Pertanyaan "kedua yaitu 'Apakah Anda mengetahui akan istilah/kata "Haram"?" Jawaban responden pada pertanyaan kedua ialah ada 2 orang responden yang menjawab tidak, sehingga dieliminasi. Pertanyaan ketika yaitu "Apakah Anda mengetahui akan istilah/kata "Obat Halal"?". Jawaban responden pada pertanyaan ketiga ialah ada 7 orang responden menjawab tidak mengetahui istilah/kata obat halal sehingga 7 orang tersebut dieliminasi. Jika ditotal seluruhnya maka ada 9 orang yang dieliminasi untuk menjawab pertanyaan berikutnya.

Tabel 2. Presentase Pengetahuan Responden Tentang Kehalalan Obat

\begin{tabular}{|c|l|c|c|}
\hline No & \multicolumn{1}{|c|}{ Pernyataan } & $\begin{array}{c}\text { Ya } \\
\mathbf{\%}\end{array}$ & $\begin{array}{c}\text { Tidak } \\
\mathbf{\%}\end{array}$ \\
\hline 1 & $\begin{array}{l}\text { Apakah Anda mengetahui bahwa pasien muslim membutuhkan obat- } \\
\text { obatan yang halal? }\end{array}$ & 98 & 2 \\
\hline 2 & $\begin{array}{l}\text { Apakah Anda mengetahui bahwa bangkai binatang, darah, babi dan } \\
\text { alkohol adalah haram untuk muslim dalam berbagai bentuk, baik itu } \\
\text { makanan, pengobatan, dll? }\end{array}$ & 96 & 4 \\
\hline 3 & $\begin{array}{l}\text { Apakah Anda mengetahui bahwa obat tersusun dari beberapa bahan } \\
\text { obat yang berasal dari babi dan bangkai binatang? }\end{array}$ & 94 & 6 \\
\hline 4 & $\begin{array}{l}\text { Apakah Anda mengetahui bahwa pilihan alternatif obat halal untuk } \\
\text { menggantikan obat yang tidak halal itu tersedia bahannya? }\end{array}$ & 88 & 12 \\
\hline
\end{tabular}




\begin{tabular}{|c|l|c|c|}
\hline 5 & $\begin{array}{l}\text { Apakah Anda mengetahui bahwa merupakan suatu kewajiban etis } \\
\text { bagi seorang dokter untuk meminta persetujuan pasien sebelum } \\
\text { meresepkan obat-obatan yang mengandung bahan yang tidak halal? }\end{array}$ & 94 & 6 \\
\hline 6 & $\begin{array}{l}\text { Apakah Anda mengetahui bahwa sebagian besar dokter dan } \\
\text { apotekermengetahui adanya komposisi,dalam obat, yang } \\
\text { mengandung bahan dari hewan-hewan yang beresiko dilarang? }\end{array}$ & 86 & 14 \\
\hline
\end{tabular}

Sumber data: primer, 2017

Berdasarkan pada tabel 2, pertanyaan yang mendapat jawaban benar paling banyak ialah pertanyaan nomor 1 yaitu sebesar $98 \%$ yang menunjukkan bahwa responden mengetahui bahwa pasien muslim membutuhkan obat yang halal. Pertanyaan yang mendapatkan jawaban benar paling banyak pada urutan kedua ialah nomor 2 yang menunjukkan bahwa responden mengetahui bahwa bangkai binatang, darah, babi dan alkohol adalah haram untuk muslim dalam berbagai bentuk, baik itu makanan, dan pengobatan. Untuk pertanyaan terkait dengan bahan obat yang halal mendapatkan nilai sebesar $94 \%$ yang termasuk tinggi. Hal tersebut menunjukkan bahwa responden telah mengetahui bahwa obat tersusun dari beberapa bahan obat yang berasal dari babi dan bangkai binatang..

Untuk jawaban responden yang mendapat nilai terendah pada pernyataan nomor 6 yaitu sekitar $86 \%$ responden menjawab ya. Hal itu menunjukkan pengetahuan responden tentang komposisi dalam obat yang mengandung bahan dari hewan-hewan yang beresiko dilarang itu kurang tinggi jika dibandingkan dengan pertanyaan yang lain. Jawaban responden dengan nilai paling rendah kedua ialah pada pertanyaan nomor 4 yaitu sekitar 88\%. Pertanyaan tersebut terkait dengan alternatif bahan obat halal. Hal tersebut menunjukkan bahwa pengetahuan responden tentang ketersediaan bahan obat halal sebagai pilihan alternatif untuk obat yang tidak halal cukup rendah dibandingkan dengan pertanyaan lain. Sehingga apabila banyak yang tidak mengetahui adanya alternatif pilihan obat halal untuk menggantikan obat yang tidah halal maka responden akan tetap memberikan obat dengan bahan yang tidak halal kepada pasien.

Tabel 3 Presentase sikap responden tentang kehalalan obat

\begin{tabular}{|c|l|c|c|c|c|c|}
\hline No & Pernyataan & $\begin{array}{c}\text { SS } \\
\mathbf{\%}\end{array}$ & $\begin{array}{c}\mathbf{S} \\
\mathbf{\%}\end{array}$ & $\begin{array}{c}\mathbf{N} \\
\mathbf{\%}\end{array}$ & $\begin{array}{c}\text { TS } \\
\mathbf{\%}\end{array}$ & $\begin{array}{c}\text { STS } \\
\mathbf{\%}\end{array}$ \\
\hline 1 & $\begin{array}{l}\text { Saya mendiskusikan dengan pasien tentang bahan } \\
\text { yang dilarang/haram dalam obat. }\end{array}$ & 19 & 73 & & 7 & 1 \\
\hline 2 & $\begin{array}{l}\text { Saya merasa suatu kewajiban moral untuk } \\
\text { memberitahukan sumber terperinci dari bahan non }\end{array}$ & 22 & 74 & & 3 & 1 \\
\hline
\end{tabular}


Tingkat Pengetahuan, Sikap, dan Persepsi Tenaga Kesehatan..

\begin{tabular}{|c|c|c|c|c|c|c|}
\hline & $\begin{array}{l}\text { halal kepada pasien (yaitu alkohol dalam } \\
\text { sirup/eliksir dan gelatin dalam kapsul). }\end{array}$ & & & & & \\
\hline 3 & $\begin{array}{l}\text { Saya meminta persetujuan pasien, jika saya tahu } \\
\text { bahwa obat tersebut tidak halal. }\end{array}$ & 25 & 69 & 0 & 5 & 1 \\
\hline 4 & $\begin{array}{l}\text { Saya mempertimbangkan kepercayaan/ agama } \\
\text { pasien ketika merancang program perawatan. }\end{array}$ & 23 & 71 & 0 & 6 & 0 \\
\hline 5 & $\begin{array}{l}\text { Saya berusaha mencari pilihan obat halal yang } \\
\text { tersedia. }\end{array}$ & 26 & 71 & 0 & 3 & 0 \\
\hline 6 & $\begin{array}{l}\text { Saya mengedukasi pasien mengenai bahan-bahan } \\
\text { yang halal. }\end{array}$ & 18 & 74 & 0 & 7 & 1 \\
\hline 7 & $\begin{array}{l}\text { Saya lebih memilih obat-obatan halal dalam praktek } \\
\text { saya. }\end{array}$ & 21 & 76 & 0 & 3 & 0 \\
\hline 8 & $\begin{array}{l}\text { Saya menyarankan pembelian obat-obatan yang } \\
\text { halal, yang mungkin saja lebih mahal. }\end{array}$ & 19 & 75 & 0 & 6 & 0 \\
\hline 9 & $\begin{array}{l}\text { Saya merasa bahwa bagi saya, perwakilan medis } \\
\text { adalah sumber informasi yang baik mengenai } \\
\text { sumber dan bahan-bahan obat. }\end{array}$ & 27 & 70 & 0 & 3 & 0 \\
\hline
\end{tabular}

Sumber: Data primer,2017

Berdasarkan tabel 3 pada tingkat sikap terhadap kehalalan obat bahwa persentase dominan responden pada sikap yang baik. Hasil penelitian menunjukkan sikap responden tentang kehalalan obat menunjukkan bahwa (19\%) responden sangat setuju, sedangkan (73\%) setuju bahwa mereka berdiskusi dengan pasien mereka tentang bahan obat yang dilarang/haram digunakan. Sebanyak (22\%) responden sangat setuju, sedangkan (74\%) setuju bahwa mereka merasa suatu kewajiban moral untuk memberitahukan sumber terperinci dari bahan non halal kepada pasien (misalnya, alkohol dalam sirup / elixir dan gelatin dalam kapsul).

Penelitian ini juga menemukan bahwa (7\%) responden tidak setuju mengedukasi pasien mengenai bahan-bahan obat yang halal, namun (74\%) responden setuju dan bahkan (18\%) sangat setuju mengedukasi pasien mengenai bahan-bahan yang halal. Penelitian lebih lanjut menemukan bahwa (25\%) responden sangat setuju bahwa mereka lebih suka obat-obatan halal dalam praktek mereka. Sebanyak (19\%) responden sangat setuju bahwa mereka merekomendasikan pembelian alternatif obat halal, yang mungkin lebih mahal meskipun (6\%) responden menyatakan tidak setuju namun (75\%) responen setuju akan merekomendasikan peberian alternative obat halal yang mungkin lebih mahal. Hal ini lebih lanjut menemukan bahwa (27\%) responden sangat setuju dan (70\%) responden setuju bahwa mereka merasa bahwa wakil-wakil medis merupakan sumber yang baik dari 
informasi tentang sumber-sumber dan bahanbahan obat bagi mereka.

Berdasarkan penelitian Sadeeqa et al (2013) bahwa sikap di pengaruhi oleh usia yang dihubungkan dengan bebrapa pernyataan. Sikap seseorang di pengaruhi oleh usia karena

Persepsi merupakan sebagai proses dimana orang dapat mengorganisasikan dan menginterpretasikan sensasi yang dirasakan dengan tujuan untuk memberi makna terhadap suatu lingkungan (Notoatmodjo, 2010).. Persepsi dalam penelitian ini digunakan untuk mengetahui persepsi tenaga kesehatan khususnya dokter dan apoteker terhadap kehalan obat.

Berdasarkan tabel 4.16 persepsi responden terhadap kehalalan obat menunjukkan bahwa total (31\%) responden sangat setuju dan (67\%) setuju, bahwa pasien memiliki hak untuk meminta informasi tentang sumber bahan dalam obat-obatan. Sementara (27\%) dari responden sangat setuju, bahwa penting untuk dokter dan apoteker untuk menjelaskan tentang sumber dan bahan obat sebanyak mungkin dan mendorong pasien untuk mengajukan pertanyaan terkait hal itu. pengalaman pribadi yang akan menimbulkan sikap positif. Usia seseorang yang semakin bertambah maka secara otomatis akan menambah pengalaman pribadi seseorang dan dipengaruhi emosionalnya (Azwar, 2013).

Namun, (32\%) responden sangat setuju dan (38\%) setuju, bahwa itu bukan praktek umum untuk menginformasikan pasien tentang sumber obat-obatan.

Penelitian ini menemukan bahwa (64\%) responden setuju dan (30\%) sangat setuju bahwa pabrik obat harus memberitahu dokter mengenai daftar dari produk mereka yang mengandung bahan/komposisi yang berasal dari binatang. Namun $(6 \%)$ responden tidak setuju akan hal itu. Sebanyak (43\%) responden sangat setuju bahwa dokter harus diedukasi tentang sumber obat-obatan. Sebanyak (63\%) responden setuju, keyakinan agama pasien dipertimbangkan saat memberikan obatobatan. Di sisi lain, (63\%) dari responden setuju, bahwa kepercayaan/ agama pasien mempengaruhi kepatuhan mereka selama terapi obat.

Tabel 4 Presentase persepsi responden tentang kehalalan obat

\begin{tabular}{|c|l|c|c|c|c|c|}
\hline No & \multicolumn{1}{|c|}{ Pernyataan } & $\begin{array}{c}\text { SS } \\
\mathbf{\%}\end{array}$ & $\begin{array}{c}\mathbf{S} \\
\mathbf{\%}\end{array}$ & $\begin{array}{c}\mathbf{N} \\
\mathbf{\%}\end{array}$ & $\begin{array}{c}\text { TS } \\
\mathbf{\%}\end{array}$ & $\begin{array}{c}\text { STS } \\
\mathbf{\%}\end{array}$ \\
\hline 1 & $\begin{array}{l}\text { Pasien mempunyai hak untuk menanyakan informasi } \\
\text { mengenai sumber bahan-bahan obat. }\end{array}$ & 31 & 67 & 0 & 2 & 0 \\
\hline 2 & $\begin{array}{l}\text { Penting bagi seorang dokter dan apoteker untuk } \\
\text { menjelaskan sebanyak mungkin tentang sumber- }\end{array}$ & 27 & 67 & 0 & 5 & 1 \\
\hline
\end{tabular}




\begin{tabular}{|c|c|c|c|c|c|c|}
\hline & $\begin{array}{l}\text { sumber dan komposisi obat serta mendorong pasien } \\
\text { untuk bertanya. }\end{array}$ & & & & & \\
\hline 3 & $\begin{array}{l}\text { Pabrik obat harus memberitahu dokter mengenai } \\
\text { daftar dari produk mereka yang mengandung } \\
\text { bahan/komposisi yang berasal dari binatang. }\end{array}$ & 23 & 48 & 0 & 15 & 14 \\
\hline 4 & $\begin{array}{l}\text { Bukan merupakan tindakan umum untuk memberi } \\
\text { informasi kepada pasien mengenai sumber-sumber } \\
\text { bahan obat. }\end{array}$ & 32 & 38 & 0 & 30 & 0 \\
\hline 5 & $\begin{array}{l}\text { Dokter dan apoteker harus diedukasi mengenai } \\
\text { sumber-sumber bahan obat. }\end{array}$ & 43 & 56 & 0 & 1 & 0 \\
\hline 6 & $\begin{array}{l}\text { Kepercayaan/ agama pasien juga dipertimbangkan } \\
\text { ketika memberikan obat. }\end{array}$ & 31 & 63 & 0 & 6 & 0 \\
\hline 7 & $\begin{array}{l}\text { Kepercayaan/ agama pasien mempengaruhi } \\
\text { kepatuhan mereka selama terapi obat. }\end{array}$ & 31 & 63 & 0 & 6 & 0 \\
\hline 8 & $\begin{array}{l}\text { Sebuah daftar tentang obat-obat yang berasal dari } \\
\text { binatang, yang paling sering digunakan serta } \\
\text { alternatif penggantinya harus dikembangkan. }\end{array}$ & 30 & 67 & 0 & 3 & 0 \\
\hline 9 & $\begin{array}{l}\text { Pabrik farmasi harus peka terhadap kewajiban } \\
\text { agama pasien dan jika memungkinkan harus } \\
\text { memproduksi obat yang halal. }\end{array}$ & 30 & 64 & 0 & 6 & 0 \\
\hline 10 & $\begin{array}{l}\text { Perusahaan obat harus secara jelas menandai } \\
\text { kemasan obat dengan label halal/ non halal yang } \\
\text { mudah dilihat. }\end{array}$ & 48 & 52 & 0 & 0 & 0 \\
\hline 11 & $\begin{array}{l}\text { Para ahli kesehatan perlu mendefinisikan kebutuhan } \\
\text { medis dan mengeksplor ketersediaan bahan-bahan } \\
\text { yang halal }\end{array}$ & 30 & 66 & 1 & 3 & 0 \\
\hline 12 & $\begin{array}{l}\text { Panduan yang jelas dan mudah dimengerti } \\
\text { merupakan hal yang dibutuhkan oleh ahli kesehatan } \\
\text { untuk mengatasi konflik menyangkut kepercayaan/ } \\
\text { agama. }\end{array}$ & 35 & 64 & 1 & 0 & 0 \\
\hline
\end{tabular}

Sumber: Data primer,2017

Penelitian ini menemukan bahwa (64\%) responden setuju bahwa pabrik farmasi harus peka terhadap kewajiban agama pasien dan jika memungkinkan harus memproduksi obat yang halal. Hal tersebut dapat menjadi evaluasi industri farmasi untuk produksi obat ke depannya. Serta sebanyak (35\%) responden sangat setuju dan (64\%) responden setuju bahwa panduan yang jelas dan mudah dimengerti merupakan hal yang dibutuhkan oleh ahli kesehatan untuk mengatasi konflik menyangkut kepercayaan/ agama. Karena halhal yang menyangkut agama dan kepercayaan menjadi hal yang cukup penting dan sensitive untuk dibicarakan terutama di negara ini yang mayoritas penduduknya beragama Islam.

Berdasarkan Sadeqaa et al (2013) bahwa karakteristik yang dihubungkan dengan 
pertanyaan persepsi menurut Kozier dalam Nurhidayat (2012), umur merupakan faktor yang dapat mempengaruhi persepsi seseorang. Umur merupakan faktor yang dapat mempengaruhi pengetahuan dan persepsi pola pikirnya.

Tabel 5 Presentase keseluruhan kategori tentang kehalalan obat

\begin{tabular}{|c|c|c|}
\hline kategori & Presentase (\%) & Keterangan \\
\hline Tingkat Pengetahuan & 96 & Tinggi \\
\hline Sikap & 97 & Baik \\
\hline Persepsi & 100 & Baik \\
\hline
\end{tabular}

Berdasarkan tabel 5 terlihat bahwa hasil penelitian menunjukkan hasil yang baik pada semua kategori yaitu tingkat pengetahuan, sikap, dan persepsi tenaga kesehatan terhadap kehalalan obat. Tingkat pengetahuan responden tentang kehalalan obat memiliki tingkat pengetahuan tinggi yaitu sebanyak 96\% sebanyak 73 responden karena nilai menunjukkan angka diatas 50\% sehingga dikategorikan memiliki tingkat pengetahuan yang tinggi. Hal tersebut dapat disesuaikan dengan pendidikan terakhir yang tinggi karena responden penelitian ini ialah orang yang berprofesi sebagai dokter dan apoteker. Hasil tersebut sejalan dengan penelitian yang dilakukan oleh Sadeeqa (2013) menunjukkan tingkat pengetahuan responden dokter dan apoteker tentang kehalalan obat terbanyak pada kategori tingkat pengetahuan baik yaitu sebanyak 141 (86\%) dari total 164 responden. seseorang. Umur dapat memepengaruhi daya tangkap seseorang dan pola pikir seseorang. Semakin bertambah usia seseorang maka semakin berkembang pula daya tangkap dan 
Tingkat Pengetahuan, Sikap, dan Persepsi Tenaga Kesehatan..

angka diatas $50 \%$ sehingga dikategorikan memiliki persepsi yang baik terhadap kehalalan obat. Hasil tersebut sejalan dengan penelitian yang dilakukan oleh Sadeeqa (2013) menunjukkan lebih dari 99\% responden mencetak $50 \%$ atau di atas, yang menunjukkan sikap positif terhadap kehalalan obat.

\section{KESIMPULAN}

Penelitian ini menunjukkan bahwa dokter dan apoteker di beberapa rumah sakit di Kabupaten Banyumas memiliki pengetahuan yang baik terhadap obat-obatan halal. Dokter dan apoteker di beberapa rumah sakit di Kabupaten Banyumas selain memiliki pengetahuan yang baik, juga memiliki sikap dan persepsi yang baik terhadap obat-obatan halal.

\section{UCAPAN TERIMA KASIH}

Ucapan terima kasih dan penghargaan penulis berikan kepada pimpinan Fakultas Farmasi Universitas Muhammadiyah Purwokerto dan pihak rumah sakit yang telah mendukung penelitian ini.

\section{DAFTAR PUSTAKA}

Arikunto, S., 2010. Prosedur Penelitian: Suatu Pendekatan Praktik. Edisi Revisi. Jakarta: Rineka Cipta

Azwar, Saifuddin, 2013. Metode Penelitian. Yogyakarta: Pustaka Pelajar

DSN MUI. Obat dan Pengobatan. Fatwa DSN MUI. No. 30 Tahun 2013 tentang Obat dan Pengobatan. 2013

Notoatmojo S., 2007. Pendidikan dan Perilaku Kesehatan. Cetakan 2., Jakarta: PT Rineka Cipta

Notoatmojo., 2010. Metodologi Penelitian Kesehatan. Jakarta: Rineka Cipta

Notoatmojo S., 2012. Promosi Kesehatan dan Perilaku Kesehatan. Jakarta: Rineka Cipta

Riyanto, Agus, 2011. Aplikasi Metodologi Penelitian Kesehatan. Yogyakarta: Nuha Medika

Sadeeqa, S., Azmi, S., Imran, M., Maryam, F., dan Muhammad Atif, 2013. Knowledge, Attitude and Perception Regarding Halal Pharmaceuticals Among General Public in Malaysia. International Journal of Public Health Science, 2(4). 143 - 150

Sadeeqa, S. dan Azmi, S. 2014. Assessment of Knowledge, Attitude and Perception Among Hospital Pharmacists Regarding Halal Pharmaceuticals. Journal of Applied Pharmaceutical Science, 4 (05). 080-086

Sadeeqa, S. dan Azmi, S., 2016. Assessment of Knowledge, Attitude and Perception Regarding Halal Pharmaceuticals Among Medical Practitioners in Malaysia. Journal of Applied Pharmaceutical Science. 4(04): 75,101,163,131

Sugiyono, 2005. Statistika untuk Penelitian. Bandung: CV Alfabeta

Sugiyono, 2010. Metode penelitian kualitatif dan kuantitatif Dan $R$ \& D., Bandung: Alfabeta 